\title{
Ontogeny of L-Glutamic Acid Decarboxylase and $\gamma$-Aminobutyric Acid Concentration in Human Kidney
}

\author{
G. A. LANCASTER, (27) F. MOHYUDDIN, AND C. R. SCRIVER \\ DeBelle Laboratory for Biochemical Genetics and the Medical Research Council Genetics Group, McGill \\ University-Montreal Children's Hospital Research Institute, Montreal, Quebec, Canada
}

Extract

Mature human renal cortex contains $\gamma$-aminobutyric acid (GABA) at concentrations on the order of $0.2 \mu \mathrm{mol} / \mathrm{g}$ wet wt and about half of that concentration in fetal kidney.

The pyridoxal-5'-phosphate (PLP)-dependent enzyme, Lglutamic acid decarboxylase (GAD), catalyzes the conversion of L-glutamate to GABA. The PLP-saturated GAD activity in post-term ( 1 day -9 years) renal cortex homogenate is $0.94 \pm 0.38$ $\mu \mathrm{mol} \mathrm{CO}_{2}$ formed/g wet wt/hr (Table 1). The corresponding GAD activity in fetal renal cortex, in the midtrimester and early third trimester, is $0.28 \pm 0.19 \mu \mathrm{mol} \mathrm{CO}_{2}$ formed $/ \mathrm{g}$ wet $\mathrm{wt} / \mathrm{hr}(P<0.01$ vs. post-term activity). GAD activity increases during gestation to reach levels at birth equivalent to mature kidney. When corrections are made for the difference in tissue water between fetal and mature kidney, they do not ablate the post-term increase in GAD activity.

Renal GAD was undersaturated with PLP in 12 of 21 specimens examined; 8 of these specimens were of fetal origin (Table 1 and Fig. 2). Undersaturation was revealed when addition of PLP $(0.24$ $\mathrm{mM}$ ) to the homogenate stimulated activity by $25-300 \%$ in the 12 specimens. GAD activity in rat kidney binds PLP avidly and is always saturated with PLP under the normal laboratory conditions of vitamin $B_{6}$ nutrition. Undersaturation of renal GAD in man may imply inadequate endogenous availability of vitamin $B_{6}$ coenzyme.

Speculation

The GABA pathway in mammalian kidney has been implicated in the maintenance of normal acid-base balance. Renal GAD is increased in the postnatal subject relative to fetal GAD activity in support of this hypothesis. Undersaturation of fetal GAD with its PLP-coenzyme in two-thirds of the fetal specimens may have implications concerning intrauterine nutrition and renal development.

In previous publications $(8,19,22)$ we described the presence of a pathway in mammalian kidney which forms GABA by the decarboxylation of L-glutamate and which then delivers the GABA via succinic semialdehyde to the tricarboxylic acid cycle. We postulated (8) that the pathway can be an effective means of disposal for the carbon chain of glutamate when it is produced from L-glutamine during renal ammoniagenesis. Conversion of glutamate, first to GABA, and then to succinate, bypasses the formation of $\alpha$-ketoglutarate which is necessary if glutamate is converted to succinate via the Krebs cycle. In this fashion, the formation of a titratable organic acid derived from glutamate can be avoided during repair of acid-base imbalance. We have shown that about one-third of endogenous glutamate oxidation in renal cortex of the rat takes place via the GABA pathway (8).

We believe that the renal GABA pathway is likely to be of particular importance in man, who extracts glutamine from the plasma to generate ammonia in kidney (10). Under such conditions, the net intrarenal burden of glutamate requiring disposal is greater than in those species, such as the rat, in which intrarenal glutamate is consumed to synthesize the glutamine used for ammoniagenesis. Renal GABA is low in rat kidney relative to human kidney (8), a finding we considered to be supportive of our hypothesis concerning the role of the GABA pathway in kidney.

We have examined the ontogeny of L-glutamic acid decarboxylase, the initial enzyme committing glutamate to the GABA pathway. GAD activity rises from low levels in the fetus to higher levels at birth and thereafter, that is, at the time endogenous control of acid-base metabolism in kidney, becomes important for adaptive purposes.

We also examined the requirement of normal human GAD for its coenzyme, pyridoxal-5'-phosphate, because of our interest in the potential relationship between the vitamin $B_{6}$ coenzyme and GAD in the hereditary convulsive disorder known as vitamin $\mathrm{B}_{6}$ dependency (19). We found that a surprising number of kidney specimens were undersaturated with respect to PLP under endogenous conditions encountered in our study.

\section{METHODS AND MATERIALS}

\section{SOURCE OF TISSUE}

Kidney was obtained from fetuses at the time of autopsy after elective prostaglandin-induced abortion; specimens were obtained from premature and post-term subjects at autopsy. The pertinent clinical information and diagnoses are listed in Table 1. If the GAD assay was not performed immediately, the intact tissue was stored at $-20^{\circ}$; GAD and GABA are stable under these conditions (8). The outer renal cortex was shaved from the frozen block of tissue and only this portion of kidney was used for assay to avoid dilution of activity with medulla, which contains little GAD or GABA (22).

\section{GAD ASSAY}

GAD was assayed at $\mathrm{pH} 6.86$ using $\mathrm{DL}-\left[1-{ }^{14} \mathrm{C}\right]$ glutamic acid and $4 \mathrm{mM} \mathrm{L-Glutamate,} \mathrm{as} \mathrm{described} \mathrm{previously} \mathrm{(8),} \mathrm{with} \mathrm{suit-}$ able correction for dilution of specific activity by the ${ }^{14} \mathrm{C}$-labeled $\mathrm{D}$ isomer. In the present study, paired assays were performed on each sample; one was performed at the endogenous concentration of PLP, the second with PLP $(0.24 \mathrm{mM})$ added to the homogenate.

\section{GABA DETERMINATION}

The concentrations of GABA and glutamate were measured by elution chromatography on ion exchange resin columns using a 
Table 1. Glutamic acid decarboxylase $(G A D)$ activity and $\gamma$-aminobutyric acid $(G A B A)$ content of human renal cortex: influence of age and puridoxal $5^{\prime}$-phosphate $(P L P)^{1}$

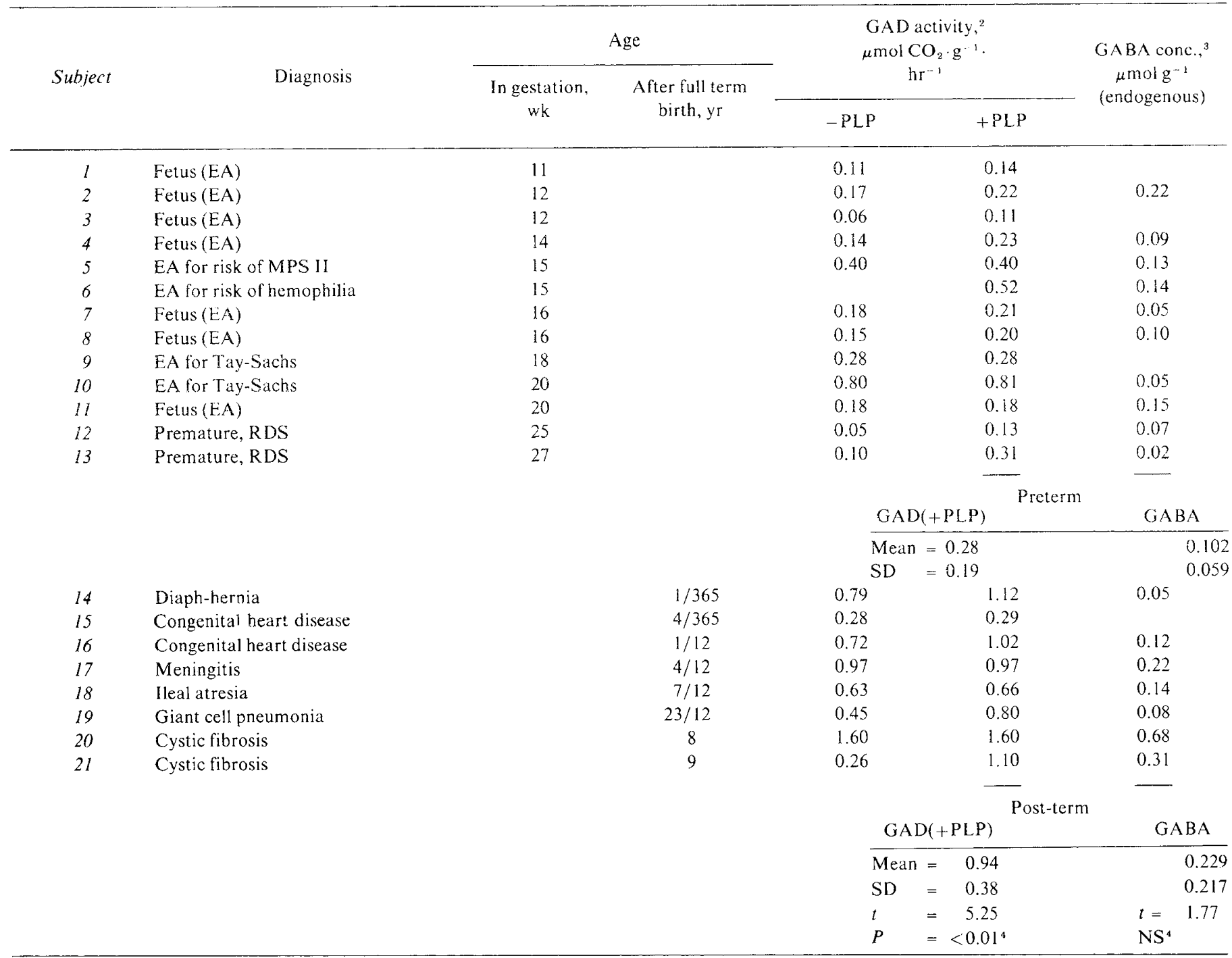

${ }^{1}$ EA: Elective abortion; RDS: respiratory distress syndrome; MPS II: mucopolysaccharidosis type II.

"GAD activity was measured first as "endogenous" activity in homogenate without added coenzyme (-PLP); and then in a paired aliquot with 0.24 mM PLP added to the reaction mixture (+PLP).

${ }^{3} \mathrm{GABA}$ was measured in deproteinized cortex homogenate without incubation.

${ }^{4}$ Preterm and post-term values compared by Student's $t$ test.

Beckman-Spinco amino acid analyzer modified for simultaneous analysis of acidic and basic amino acids (18). The tissue was homogenized and deproteinized before analysis as described previousiy (8).

The change in water content of fetal and post-term kidney cortex was taken into account when interpreting GAD activity and amino acid content. Total tissue water in renal cortex was determined by drying slices to constant weight.

\section{RESULTS}

\section{GAD ACTIVITY}

The mean activity for the PLP-saturated enzyme (holoenzyme) rises from a nadir in midtrimester kidney, to a post-term plateau (Fig. 1). GAD activity in mature kidney, when expressed as a function of wet weight, is four or fivefold greater than in fetal kidney. The difference between preterm and post-term GAD activity is statistically significant $(P<0.01)$. When the appropriate correction is made for the higher total tissue water of fetal kidney, compared with the mature tissue, the GAD activity in post-term kidney is still two to threefold greater than in fetal tissue.

In the absence of PLP-saturation of GAD apoenzyme in vitro, the pattern of GAD ontogeny is less consistent (Table 1). The reason for this lies in a noticeable undersaturation of the apoenzyme by its coenzyme in many of our samples (see below).

\section{CONCENTRATION OF GABA AND GLUTAMATE IN KIDNEY CORTEX}

The concentration of GABA in fetal kidney is $0.102 \pm 0.059$ $\mu \mathrm{mol} \cdot \mathrm{g}$ wet $\mathrm{wt}^{-1}$ (Table 1 ). The higher concentration in postterm kidney is confirmed when GABA content is expressed as a coefficient of kidney cortex dry weight. Although the mean post-term concentration is higher than in preterm kidney, the observed difference was not significant by Student's $t$ test. Our present observations on the GABA content in post-term human kidney cortex conform satisfactorily with earlier data reported for autopsy specimens by two groups of workers (mean, 0.23 , range $0.11-0.44 \mu$ moles $\cdot g$ wet $\left.w^{-1}\right)(22,24)$.

Cortical glutamate content did not exhibit any consistent age-dependent variation. The intracellular concentration of gluta- 
mate is about $4 \mathrm{mM}$ in preterm and post-term human kidney cortex, indicating that a change in glutamate content is not the source of the changing GABA content or GAD activity.

\section{RELATIONSHIP BETWEEN GAD ACTIVITY AND PLP ADDED IN VITRO}

Significant stimulation of GAD activity in the presence of exogenous PLP was encountered in 12 of 21 specimens examined by the paired assay (Table 1). The relationship between basal and PLP-stimulated activity is hyperbolic (Fig. 2), indicating maximum under-saturation of endogenous apoenzyme, at low basal levels of GAD apoenzyme.

\section{DISCUSSION}

Renal GAD is a mitochondrial enzyme whose properties are different from those of brain $\operatorname{GAD}(6,8,22)$. The renal enzyme is less readily inhibited by carbonyl-trapping agents, and it is stimulated by chloride ion. The conversion of glutamate to GABA is not a reversible reaction in mammalian tissues. The subsequent conversion of GABA to succinate supports respiration in kidney $(8,22)$. The aminotransferase required to transaminate GABA to succinic semialdehyde is abundant in mature mammalian kidney

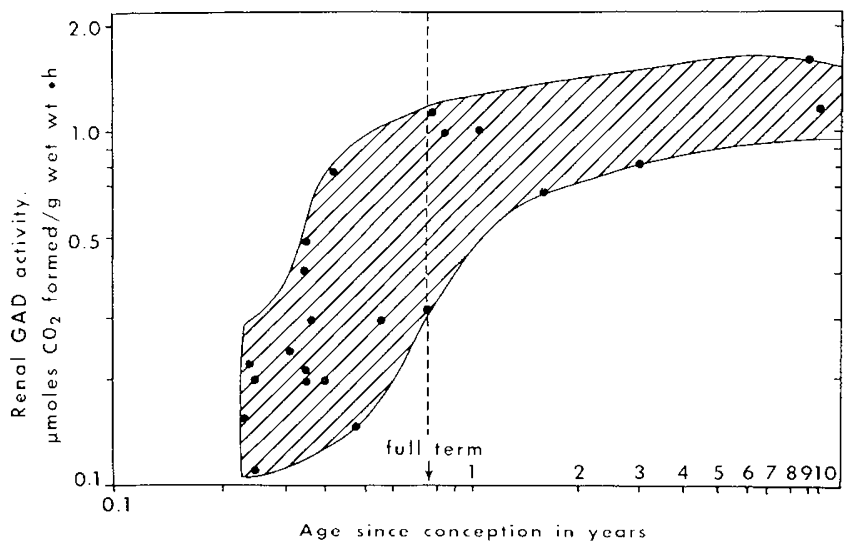

Fig. 1. Age-dependent specific activity of L-glutamic acid decarboxylase $(G A D)$ in homogenates of human renal cortex homogenates. Values for GAD holoenzyme activity were obtained with a saturating concentration of pyridoxal-5'-phosphate coenzyme $(0.24 \mathrm{mM})$ added to the homogenate. Fetal GAD activity is significantly lower than post-term activity $(P<$ 0.01 ). The pattern of GAD ontogeny is not significantly altered when activity is expressed as a coefficient of dry weight instead of wet weight.

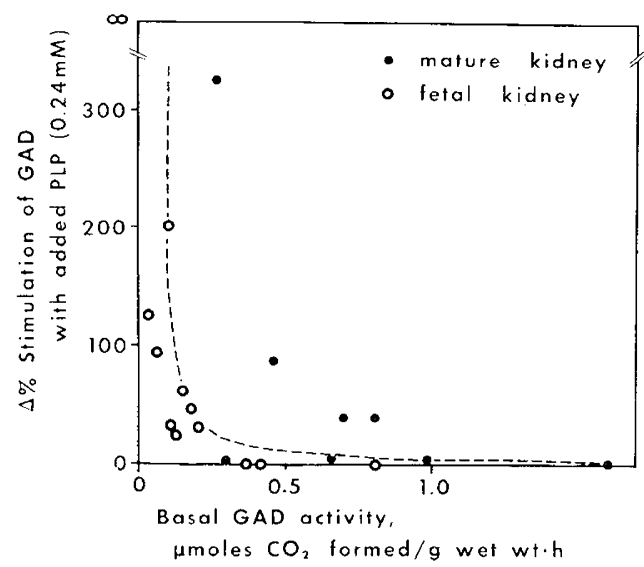

Fig. 2. The relation between basal GAD activity in human renal cortex and its ability to undergo stimulation when a saturating amount of pyridoxal-5'-phosphate $(P L P)(0.24 \mathrm{mM})$ is added to the homogenate. Undersaturation of L-glutamic acid decarboxylase $(G A D)$ apoenzyme by its coenzyme $(P L P)$ is apparent in 12 of the 21 specimens; 8 of the 12 are fetal specimens.
(8), and the rate-limiting enzyme in the GABA pathway is GAD (8). GAD and GABA- $\alpha$-ketoglutarate aminotransferase are in different subcellular compartments in brain $(5,21)$; their distribution in kidney, presumed to be comparable to that in brain, awaits clarification. GABA does not have an important presynaptic, neuroinhibitory role in kidney, as it does in brain (2), yet this amino acid is present at higher concentration in renal cortex than in any other non-neural tissue, and in greater concentration in kidney of man than in other species $(6,8,20)$. The GABA pathway can oxidize a considerable fraction of the intracellular glutamate, both in kidney (8) and brain $(14,16)$. Such observations led us to propose that the GABA pathway may be important in the support and repair of acid-base metabolism in kidney, particularly in man, where the large concentration of renal GABA and ample GAD activity coincide with his known capacity to extract glutamine from plasma (11) to provide ammonia for titration of hydrogen ion. We suggest that the ontogeny of renal GAD, the enzyme that commits the carbon of glutamate to the GABA pathway during ammoriagensis, fits our hypothesis. Acid-base metabolism in the fetus is accommodated by the mother through the placenta; in this circumstance there is no demand on the renal GABA pathway. The post-term increase in renal GAD specific activity coincides with the need for the infant to adapt to the demands of acid-base metabolism after birth.

If $\mathrm{GABA}$ is the product of GAD, one anticipates a close correlation between renal GABA and GAD during the process of ontogeny. This is not the case, although amino acid and enzyme do both increase perinatally. The quasi-independent ontogeny of renal GABA probably reflects the independent removal of GABA by its aminotransferase. Others have shown that steadystate levels of GABA in tissue observe a complex relationship between the rates of synthesis and removal (23). The more cumbersome transaminase assay was not conducive to examination for its pattern of ontogeny in the present study, and was not considered an essential component of our primary hypothesis, that the activity of the GAD enzyme which initiates the pathway should parallel the demand for acid-base regulation in postnatal life.

We encountered an unexpected observation pertaining to the GAD holoenzyme in human kidney. Our earlier studies with rat kidney GAD (8) indicated that activity could not be enhanced by the addition of PLP to the tissue homogenate. The animals used in the earlier studies were fed on rat chow containing ample vitamin $\mathrm{B}_{6}$, and we subsequently observed that the rat enzyme, once it has bound PLP, avidly retains its coenzyme so that undersaturation would be an unlikely occurrence, unless the animal was initially deprived of vitamin $B_{6}(4)$. Therefore, evidence for undersaturation of human renal GAD by its coenzyme implies that availability or binding of coenzyme was impaired in a number of the tissue specimens examined in the present study. Vitamin $B_{6}$ depletion at the time of death would not be surprising in some of the terminally ill patients we studied, but to find significant undersaturation of the enzyme in 8 of the 13 fetal kidney specimens is noteworthy.

Our observation implies that maternal vitamin $B_{6}$ nutrition may occasionally be inadequate and sufficient vitamin precursor may not be provided to fetal tissues to permit maximal coenzyme synthesis in situ in order to saturate GAD. Some infants do indeed have low blood PLP levels at birth (17), presumably reflecting the status of intrauterine vitamin $B_{6}$ nutrition. It is unlikely that maternal tissues provide preformed PLP to the fetus, since the phosphorylated aldehyde is poorly taken up by the intact cell (15), and extracellular concentrations of PLP are normally low relative to tissue levels $(1,7)$. A generalized impairment in the fetus of PLP biosynthesis $(12,13)$ seems unlikely since the fetus would not sustain any PLP-dependent apoenzyme activity if this were a general pattern of ontogeny. The possibility that fetal GAD is different from postnatal GAD in its properties for PLP binding deserves consideration and merits investigation. The possibility that renal cortex development might be compromised by inadequate vitamin $\mathrm{B}_{6}$ nutrition in utero should be kept in mind now 
that this phenomenon has been reported for the rat by DiPaulo and colleagues (3).

\section{SUMMARY}

GAD activity and GABA, the product of GAD action on L-glutamate, are both prominent in mature human renal cortex. GAD activity is low in fetal kidney but rises several fold preterm to establish the characteristic post-term specific activity. The ontogeny of the initial step in the GABA pathway parallels the need for kidney to accommodate acid-base regulation after birth. PLP coenzyme is required for GAD holoenzyme integrity. Fetal renal GAD was frequently undersaturated with PLP in our series of observations, raising the suggestion that maternal vitamin $B_{6}$ nutrition is not always adequate.

\section{REFERENCES AND NOTES}

1. Bain, J. A., and Williams, H. L.: Concentrations of $B_{6}$ vitamins in tissues and tissue fluids. In: E. Roberts: Inhibition in the Nervous System and $\gamma$ Aminobutyric Acid, p. 275 (Pergamon Press, New York, 1960)

2. De Groat, W. C., Lalley, P. M., and Saum, W. R.: Depolarization of dorsal root ganglia in the cat by GABA and related amino acids: Antagonism by picrotoxin and bicuculline. Brain Res., 44: 273 (1972).

3. Di Paolo, R. V., Caviness, V. S. Jr., and Kanfer, J. N.: Delayed maturation of the renal cortex in the vitamin $B_{6}$-deficient newborn rat. Pediat. Res. 8: 546 (1974)

4. Goodyer, P., Lancaster, G., Mohyuddin, F., and Scriver, C. R.: Unpublished observations (1973)

5. Haber, B., Kuriyama, K., and Roberts, E.: Mitochondrial localization of a new L-glutamic acid decarboxylase in mouse and human brain. Brain Res., 22: 105 (1970).

6. Haber, B., Kuriyama, K., and Roberts, E.: An anion stimulated L-glutamic acid decarboxylase in non-neural tissues. Biochem. Pharmacol., 19: 1119 (1970).

7. Hines, J. D., Love, D. S., and Peart, M. B.: Determination of serum and blood pyridoxal phosphate concentrations with purified rabbit skeletal muscle phosphorylase b. J. Lab. Clin. Med., 73: 343 (1969).

8. Lancaster, G., Mohyuddin, F., Scriver, C. R., and Whelan, D. T.: A $\gamma$ aminobutyric pathway in mammalian kidney cortex. Biochim. Biophys. Acta, 297: 229 (1973)

9. Lancaster, G., Mohyuddin, F., and Scriver, C. R.: Age-dependent activity of L-glutamic acid decarboxylase (GAD) in human kidney (Abstract). Pediat. Res., 8: 358 (1974)

10. Lyon, M. L., and Pitts, R. F.: Species differences in renal glutamine synthesis in vivo. Amer. J. Physiol., 216: 117 (1969).

11. Marliss, E. B., Aoki, T. T., Pozefsky, T., Most, A. S., and Cahill, G. F., Jr Muscle and splanchnic glutamine and glutamate metabolism in postabsorptive and starved man. J. Clin. Invest., 50: 814 (1971)

Copyright (c) 1975 International Pediatric Research Foundation, Inc.
12. McCormick, D. B., Gregory, M. E., and Snell, E. E.: Pyridoxal phosphokinase. I. Assay, distribution, purification and properties. J. Biol. Chem., 236: 2076 (1961).

13. McCormick, D. B., and Snell, E. E.: Pyridoxal phosphokinase. II. Effects of inhibitors. J. Biol. Chem., 236: 2085 (1961).

14. McKhann, G. M., Albers, R. W., Sokoloff, L., Mickelsen, O, and Tower, D. B The quantitative significance of the gamma-aminobutyric acid pathway in cerebral oxidative metabolism. In: E. Roberts: Inhibitions in the Nervous System and $\gamma$-Aminobutyric Acid, p. 169 (Pergamon Press, London, 1960).

15. Pal, P. N., and Christensen, H. N.: Uptake of pyridoxal and pyridoxal phosphate by Ehrlich ascites tumor cells. J. Biol. Chem., 236: 894 (1961)

16. Patel, A. J., Balazs, R., and Richter, D.: Contribution of the GABA bypath to glucose oxidation and the development of compartmentation in the brain. Nature, 226: 1160 (1970).

17. Reinken, L., and Mangold, B.: Pyridoxal phosphate values in premature infants Int. J. Vit. Nutr. Res., 43: 472 (1973).

18. Scriver, C. R., Davies, E., and Lamm, P.: Accelerated selective short column chromatography of neutral and acidic amino acids on a Beckman-Spinco analyzer modified for simultaneous analysis of two samples. Clin. Biochem., $I$. 179 (1968).

19. Scriver, C. R., and Whelan, D. T.: Glutamic acid decarboxylase (GAD) in mammalian tissue outside the central nervous system and its possible relevance to hereditary vitamin $B_{6}$ dependency with seizures. Ann. N. Y. Acad. Sci., 166 : 83 (1969).

20. Von Seiler, N., and Wiechmann, M.: Zum Vorkommen der $\gamma$-aminobuttersaure und der $\boldsymbol{\gamma}$-amino- $\beta$-hydroxy-tuttersaure in Tierischem Gewebe. Hoppe-Seyler's Z. Physiol. Chem., 350: 1493 (1969).

21. Waksman, A., and Bloch, M.: Identification of multiple forms of aminobutyrate transaminase in mouse and rat brain: Subcellular localization. J. Neurochem. 15: 99 (1968).

22. Whelan, D. T., Scriver, C. R., and Mohyuddin, F.: Glutamic acid decarboxylase and gamma-aminobutyric acid in mammalia n kidney. Nature, 224:916 (1969).

23. Wood, J. D., and Peesker, S. J.: Development of an expression which relates the excitable state of the brain to the level of GAD activity and GABA conten with particular reference to the action of hydrazine and its derivatives. $J$. Neurochem., 23: 703 (1974).

24. Zachmann, M., Tocci, P., and Nyhan, W. L.: The occurrence of $\gamma$-aminobutyric acid in human tissues other than brain. J. Biol. Chem., 241: 1355 (1966).

25. This work was presented at the annual meeting of the Society for Pediatric Research in Washington, May 1974 (9).

26. We wish to thank Dr. H. Goldman and Ms. J. Grove of the McGill Unit for Antenatal Diagnosis for the fetal tissue and Cyril Adams for the amino acid analyses.

27. This work was supported by a grant from the Medical Research Council to the McGill University-Medical Research Council Group in Medical Genetics and from the Quebec Network of Genetic Medicine.

28. Requests for reprints should be addressed to: G. A. Lancaster, Ph.D., McGil University-Montreal Children's Hospital Research Institute, 2300 Tupper St., Montreal H3H 1P3, Quebec, Canada.

29. Accepted for publication January 10, 1975. 